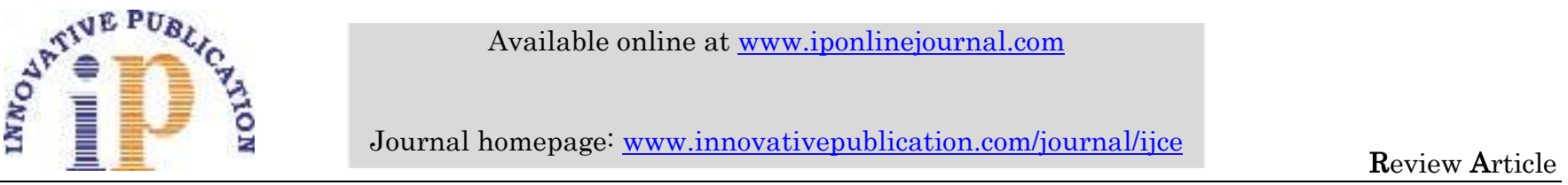

\title{
Biomarker of health and disease in Dentistry: Proteomics
}

\author{
Vamsee Krishna $\mathbf{N}^{1^{*}}$, Madhuri Nadhamuni ${ }^{2}$ \\ ${ }^{1}$ Associate Professor, ${ }^{2}$ Clinical Practitioner, ${ }^{1}$ Dept. of Conservative Dentistry and Endodontics, CKS Teja Institute of Dental Sciences and \\ Research, Tirupati, Andhra Pradesh, ${ }^{2}$ Tirupati, Andhra Pradesh, India
}

\begin{abstract}
Every living organism contains 'Proteins' which are building blocks to perform various functions. Proteomics is the analysis of the whole protein in a genome which tells about the molecular mechanisms of homeostatic cell and regarding external disturbances, such as pathologic or pharmacologic treatment. Proteomics improvized various biomedical fields such as medicine, dentistry, molecular biology, and genetics. This article reviews some of the currently available literature on conducting Proteomic analysis of dental tissues. A literature review is done using electronic databases, such as "PubMed," "Google Scholar," and "Scopus," using keywords "Proteomics," and "Biomarkers." Furthermore, an advanced or refined search was carried out using the keywords "Mass Spectrometry," "Proteins," "Enamel," "Dentin," "Cementum," "Periodontal ligament" and "pulp." Proteomics in dentistry helps in the early diagnosis of healthdisease molecular signatures with the discovery and recognition of numerous biomarkers in biological, pathological or pharmacological processes that are present in the fluids of the oral cavity. This paper explains the role of proteomics in the analysis of oral tissues.
\end{abstract}

Keywords: Proteomics, Mass Spectrometry, Biomarkers.

Key Message: Proteomics is an emerging field of analytical research that helps in the understanding of diagnosis, and pathogenesis of various diseases which helps in the prognosis and treatment plan.

\section{Introduction}

The oral cavity harbors a wide variety of $65 \%$ bacteria, $30 \%$ fungi and $5 \%$ of other organisms. ${ }^{1}$ The human oral cavity contains hard tissues, i.e. Enamel, Dentin \& Alveolar bone, soft tissues, i.e. Pulp, Periodontal ligament \& Gingiva, and various biofluids like saliva and crevicular fluid. With the identification of microorganisms, disease initiation, progression, resistance, treatment plan \& failures can be assessed. The culture technique has been the standard and oldest method of detecting the microorganisms involved in diseases. The disadvantages of phenotypic identification are it is impossible to culture a large number of microorganisms, time-consuming, need for transporting media and immediate processing, low specificity \& sensitivity, and operator expertise. All species can't be cultured due to their specific growth factors, nutritional requirements, and also the harmful substances released by other organisms can hamper the culture technique. Hence the culture technique, which is considered as a gold standard, is not entirely justified. This has paved the way for culture-independent methods which are rapid and can directly analyze the sample with high sensitivity and specificity. A literature review is conducted using electronic databases, such as "PubMed," "Google Scholar," and "Scopus," using keywords "Proteomics," and "Biomarkers." Furthermore, an advanced or refined search was carried out using the keywords "Mass Spectrometry," "Proteins," "Enamel," "Dentin," "Cementum," "Periodontal ligament" and "pulp." This article reviews some of the currently available literature on conducting Proteomic analysis of dental tissues.

The human body contains different types of proteins which regulate the structural, catalytic, storage, transport, and transducer mechanisms of cells. Hence proteins are called "working horses" of a cell. Proteins are made up of 20 different types of amino acids that are linked with each other by peptide bonds. ${ }^{2}$ Mark Wilkins first introduced the term "Proteome" in 1961. ${ }^{3}$ The complete set of proteins expressed in a given cell or biological sample is termed as proteome, and its study is called "proteomics." Proteomics research includes the sample preparation and protein/peptide separation followed by identification, quantitative, qualitative, and functional characterization of the whole protein profile of a given cell, tissue, and/or organism by using proteomics tools such as polyacrylamide gel electrophoresis (2D-Gel), mass spectrometry (MS), real time-PCR, microarrays and chromatographical tools. ${ }^{5-7}$

Proteomics helps in understanding the mechanisms of bacterial resistance, virulence, and how bacteria interact with human cells and thus, of the pathogenesis of infectious diseases. Proteomic tools can analyze different hard \& soft tissues samples and fluid samples of the oral cavity in both physiological and pathological conditions. ${ }^{8-10}$ Commonly used methods for separating proteins are 2D gel electrophoresis and liquid chromatography. 2D gel electrophoresis is commonly used to separate a mixture of

\footnotetext{
*Corresponding Author: Vamsee Krishna N, Dept. of Conservative Dentistry and Endodontics, CKS Teja Institute of Dental Sciences and Research, Tirupati, Andhra Pradesh, India

Email: dr.vamseekrishna@gmail.com

http://doi.org/10.18231/j.ijce.2019.016
} 
proteins into single detectable protein spots. The 2D separation of proteins on the gel is usually achieved according to their isoelectric point and molecular weight. The advantages of the 2D gel electrophoresis are its consistency and high resolution. The insolubility of membrane proteins is still a main obstacle for 2Delectrophoresis. The ionic detergents used for solubilization of membrane proteins can interfere with the focusing process. Additionally, the mass range and the detection limits also represent technical limitations of 2Delectrophoresis method.

The proteins that are separated on 2D gels traditionally are stained by silver staining and Coomassie blue. However, these detection methods remain problematic due to low sensitivity (for Commassie) or poor reproducibility and dynamic range (for silver). The recent development of fluorescent dyes, namely SYPROTM Ruby, overcame these problems with its sensitive (1-2 ng) detection limits and linear dynamic range over three orders of magnitude. The resulting $2 \mathrm{D}$ map is then analyzed by software designed for image analysis, which allows gel-to-gel comparison. Following 2D image analysis, the protein spot of interest is excised and treated with ammonium bicarbonate and acetonitrile to remove detergents. The excised spots are then in-gel-digested with a protease (trypsin is commonly used) in an optimal buffer for its activity. The digested peptides are then easily eluted from the gel to undergo mass spectrometry analysis.

Mass spectrometry (MS) is a technique where the mass of an ion is measured for the characterization of the molecule of interest. Mass spectrometry is composed of a sample inlet, an ionization source, a mass analyzer, and a detector. Mass spectrometry helps in identification and characterization of thousands of proteins rapidly in a sample. The traditional ionization fragmentation of peptides does not provide accurate peptide mass. However, matrixassisted laser desorption/ionization (MALDI)) and electrospray ionization (ESI) enabled the ionization of large biological macromolecules without fragmentation for the identification of proteins. Databases are available for theoretical digests of all known proteins. Matching the peptide-mass data obtained from a sample of interest to theoretically digested protein database can be used to identify unknown proteins successfully. ${ }^{11}$ The proteomics of body fluids is conducted by two methods using MS. In topdown proteomics, intact proteins are analyzed using MALDI or ESI, and by gas-phase fragmentation method, the peptides are generated. ${ }^{12}$ The bottom-up analysis also called "shotgun proteomics" is the more conventional approach \& is used for analyzing peptides produced through chemical or enzymatic cleavage of proteins with posttranslational modification as well as through liquid chromatography (LC) in conjunction with MS. ${ }^{13}$

Mrozik et al., compared proteomes between bone marrow, periodontal ligaments (PDL), and dental pulp using 2-DE, MS/MS. ${ }^{14}$ Salmon et al., identified a novel biomarker, 'superoxide dismutase-3' associated with cementum cells through his proteomics study of dental cementum using LC-MS/MS and also detected 231 proteins related to cementum. ${ }^{15}$ Dame et al., used a variety of proteomics analytical tools including MS, direct flow injection/liquid chromatography, inductively coupled plasma mass spectrometry, gas chromatography, nuclear magnetic resonance spectroscopy, and high-performance liquid chromatography, in his study to calculate 308 salivary metabolites. $^{16}$

With the help of different proteomic tools and numerous biomarkers present in the oral fluids, a drastic change occurred in dentistry in early diagnosis, treatment with minimal interventions, and prevention of dental diseases. Dental samples for proteomics analysis are collected from dental hard tissues (enamel, dentin, cementum), soft tissues (pulp, gingiva, periodontal ligament $\&$ oral mucosa) and oral fluids such as saliva and gingival crevicular fluids (GCF). The tooth is the strongest calcified part in the human body, which is made up of three distinct highly mineralized hard tissues enamel, dentine, cementum, and soft tissue is the pulp. The Periodontal ligament is the connective tissue that surrounds, attaches, and suspends the tooth inside the alveolar socket.

Proteomic analysis of dental hard tissues must overcome many methodological hurdles. One is the need to remove calcium and other minerals from the calcified tissues. The other problem is poor solubility and low abundance of matrix proteins resulting in a very less yield of proteins during processing. Another difficulty is the substantial protein heterogeneity associated with alternative splicing and a variety of post-translational modifications. ${ }^{17}$ Conrads et al. were the first to make molecular biological approach in Endodontics. Kary Mullis developed Polymerase chain reaction (amplification) which helped in isolation of previously unknown species from endodontic infection- B. forsythus and T. denticola, Dialister pneumosintes and Filifactor alocis, T. parvum and T. putidum. $^{18-20}$

\section{Proteomics of dental hard tissues}

The only dental hard tissue of ectodermal origin is Enamel. It is formed by ameloblasts before the eruption of teeth with an acellular structure, exposed to calcification in the absence of blood vessels and nerves. It is composed of $96 \%$ inorganic, $1 \%$ organic, and $3 \%$ water by weight, in which the organic substance consists of proteins, carbohydrates, and lipids. The protein content in the enamel is only a small fraction of the entire mass ranging from $0.5 \%$ and $3 \%-4 \%$. The enamel proteins are $0.17 \%$ acid-soluble, $0.18 \%$ acidinsoluble peptides, and $0.15 \%$ free amino acids, $0.6 \%$ lipids, and $0.1 \%$ citrates. $^{21}$ In developing teeth, the secretory-stage enamel contains $>30 \%$ protein. By evaluating the changes in protein content of enamel through proteomics, physiological \& pathological changes in the enamel can be studied and predicted in an early stage. ${ }^{8}$

Amelogenin, ameloblastin, enamelin, and tuftelin are the major enamel proteins. ${ }^{22}$ Amelogenin is the main 
structural protein for enamel formation, and it regulates the initiation and growth of hydroxyapatite crystals during the mineralization of enamel. Ameloblastin is an enamelspecific extracellular matrix glycoprotein secreted by ameloblasts. It is believed to be controlling the elongation of enamel crystals and helps in enamel mineralization process during tooth development thereby maintaining the rod integrity. $^{23-24}$ Vymetal et al., observed the expression of ameloblastin in developing mesenchymal dental hard tissues, and in trauma-induced reparative dentin during early craniofacial bone formation ${ }^{25}$ Enamelin is first formed as a soft, protein-rich extracellular matrix, which is essential for enamel formation. The studies conducted by Brookes, Hu, and Yamakoshi proved that enamelin is critical for proper enamel formation as mutations in the enamelin gene cause amelogenesis imperfecta. ${ }^{26-28}$ Tuftelin stimulates the initiation of the mineralization during tooth development by acting as a nucleator for hydroxyapatite crystal formation. In enamel hypomineralization, the enamel defects appear as opaque, yellow or brown discoloration and these changes are accompanied by an increased protein content when compared to sound enamel. The elevated levels of serum albumin and presence of antithrombin \& antitrypsin were observed that inhibit apatite crystal growth. ${ }^{29}$

Dentin forms the main bulk of the tooth. It protects the pulp as well as brace the overlying enamel and cementum. It is composed of $70 \%$ minerals, $20 \%$ organic, and $10 \%$ Water by weight. ${ }^{2}$ Many studies were done using one-dimensional sodium dodecyl sulfate-polyacrylamide gel electrophoresis (SDS-PAGE) followed by tandem mass spectrometry for identification of the human dentin proteins. ${ }^{30-32}$ Odontoblasts secrete the proteins which play a key role in dentin extracellular matrix organization and the regulation of mineralization during dentinogenesis. ${ }^{33-34}$ The proteins by producing enzymes modify the functions and act as nucleators by regulating ion transport in the extracellular matrix formation or prevent the mineral formation in unwanted sites. ${ }^{35}$ Proteomics helps in identification of collagenous and non-collagenous proteins in dentine. The principal collagenous proteins identified in the dentin are matrix metalloproteinase 2 (MMP-2), matrix metalloproteinase 9 (MMP-9), and matrix metalloproteinase 20 (MMP-20). ${ }^{36-38}$ The dentin sialophosphoprotein (DSPP) is the major noncollagenous protein identified in human dentin. Lee et al. stated that dentin dysplasia type II, and dentinogenesis imperfecta types II and III are caused due to genetic defects in dentin sialophosphoprotein. ${ }^{39,40}$ Sialic acid-rich proteins are another group of non-collagenous protein which includes osteonectin, osteocalcin, osteopontin, bone sialoprotein, bone acidic glycoprotein, dentin matrix protein I, and integrin-binding sialoprotein. ${ }^{41}$ These proteins also play a role in the process of dentin mineralization. Proteoglycans and hydroxyapatite crystals have been identified in predentin and dentin. ${ }^{42-44}$

Dental cementum is a bone-like avascular and noninnervated mineralized tissue that covers the root and anchors the periodontal ligament which binds the tooth to the alveolar bone. It is produced by specialized cells called cementoblasts and is slightly softer than dentin and consists of about 45-50\% inorganic (apatite crystals), 50-55\% organic (collagen and glycoproteins) and water by weight. $^{45,46}$ The predominant extracellular matrix component of cementum is type I collagen. The noncollagenous proteins like glycoproteins (e.g., osteonectin and arginine-glycine-aspartic acid integrin-binding proteins), proteoglycans (e.g., versican, decorin, and biglycan), and other proteins (e.g., osteocalcin, matrix Gla protein, and protein $\mathrm{S}$ ) constitute the remaining organic matrix of dental cementum. All these proteins participate in the matrix deposition and mineralization, regulation of cell metabolism, and thus contributes to determining the structure and biomechanical properties of the tissue. ${ }^{8,15}$

\section{Proteomics of dental soft tissue}

The dental pulp is the uncalcified soft connective tissue located within the pulp cavity, surrounded by hard dental tissues. It forms the dentin, aids in sensory function and provides tooth nourishment and immune defense reactions, and demonstrates strong repair \& regenerative potential. It is composed of cells (odontoblasts, fibroblasts, mesenchymal) nerve fibers, blood vessels, and lymphatics. ${ }^{47,48}$ Paakkonen et al. reported the first proteomic study of dental pulp using Two-dimensional gel electrophoresis followed by Tandem mass spectrometry. ${ }^{49}$ In an in vitro proteomic study of the dental pulp, 23 proteins related to early odontogenetic differentiation were identified by difference gel electrophoresis followed by MS. ${ }^{50}$ The dental pulp contains unique tissue-specific proteins and small leucine-rich proteoglycans like biglycan, lumican, and mimecan. ${ }^{51}$ Paakkonen et al., analyzed for the first time the gene and protein expression in healthy and carious dental pulp organs using cDNA microarray and 2D-gel electrophoresis and identified 96 proteins. ${ }^{49}$ McLachlan et al. studied dental pulp tissues for detailed characterization, and molecular changes in dental caries and a total of 445 genes were identified out of which 85 genes were reported abundant in health and 360 abundant in disease. ${ }^{52}$

Periodontal ligament (PDL) is the connective tissue which helps in maintaining PDL space, anchorage and provides regeneration or repair of the periodontium in response to disease and mechanical trauma. Reichenberg et al. reported a first study on periodontal ligament (PDL) fibroblast proteome for understanding its physiology and identifying disease-related protein markers. ${ }^{53}$ On exploring the early osteogenic differential protein-profile in human PDL cells, 29 proteins were identified which have been primarily linked to the cell membrane-binding, cytoskeleton, nuclear regulations, matrix synthesis signal conduction, and metabolic enzymes that participate in the intra- and inter-cellular processes. ${ }^{54-56}$

\section{Oral fluid proteomics}

Collection of Oral Fluids (saliva and GCF) for proteomic analysis is a noninvasive technique and causes minimal 
patient discomfort and anxiety. ${ }^{57}$ Saliva which is produced by the major and minor salivary glands is composed of water, proteins, peptides, hormones, lipids, sugars, and ions. ${ }^{58}$ The proteins in saliva are differentially expressed in secretions, depending on the salivary gland that secretes them. The predominant proteins and peptides in the whole saliva include amylase, carbonic anhydrase, mucins, cystatins, histatins, statherin, and proline-rich proteins. ${ }^{59,60}$ Cystatins and mucins are the salivary defense proteins. ${ }^{61}$

The acquired enamel pellicle is a thin layer $(0.5-1 \mu \mathrm{m})$ of mucins, glycoproteins, and proteins formed on the enamel surface by selective adsorption of salivary compounds. ${ }^{62}$ It plays an important role in the crystal growth homeostasis and the physicochemical defense of tooth surfaces. ${ }^{63}$ Siqueira et al. by analyzing a global proteome of the human pellicle identified 130 proteins and grouped into three types. The first group proteins bind to calcium ions $(18 \%)$, the second group $(15 \%)$ bind to phosphate ions, and the third group (28\%) interacts with the other proteins. ${ }^{64}$ Disease-related salivary biomarkers were summarized (i.e., for hereditary and autoimmune diseases, malignancies, dental caries, periodontal diseases) and identified by various studies of salivary proteomics. ${ }^{65,66}$

The protein composition and content of human gingival crevicular fluid (GCF) varies based on periodontal health and disease. GCF contains serum transudate in the gingival sulcus, subgingival microbial plaque, extracellular proteins, host inflammatory mediators, and cells. ${ }^{67}$ Many noninvasive methods are available for the collection of GCF such as gingival wash, capillary tubes, paper strips, and cones. The paper strip is mostly used for the collection of GCF due to easy insertion into the gingival crevice up to $1 \mathrm{~mm}$ of sulcular depth without bleeding from periodontal pockets. ${ }^{68}$ GCF volume for proteomic analysis is limited due to the severity of tissue inflammation. ${ }^{69}$

\section{Conclusion}

The role of microorganisms in causing the dental infections is well established, and identification of microbial taxonomy serves as a rationale for setting the clinical protocols. Culture technique has been the common diagnostics method for infectious diseases for many years. Due to factors like time consumption, low sensitivity and specificity of culture techniques led to the era of molecular analysis of sample. The proteomic research of human teeth has a high impact on the understanding of various diseases, not only on dental caries. The overall analysis on proteomics in dentistry shows that more studies are directed toward the structural formation, diagnosis, and pathogenesis and limited studies have been done on evaluation of treatment, the prognosis of interventions, and prevention of diseases.

\section{Source of Funding}

None.

\section{Conflict of Interest}

None.

\section{References}

1. Madhu KS, Mathew S. Review of microbiology of endodontics and molecular identification of microorganisms from endodontic infections. J Otolaryngol ENT Res 2018;10:417-20.

2. Khurshid Z, Zohaib S, Najeeb S, Zafar MS, Rehman R, Rehman IU et al. Advances of Proteomic Sciences in Dentistry. Int J Mol Sci 2016;17:728. doi:

10.3390/ijms17050728.

3. Wilkins M. Proteomics data mining. Expert Rev Proteomics 2009;6:599-603.

4. Khurshid Z, Zohaib S, Najeeb S, Zafar MS. Proteomics Advancements in Dentistry. J Dent Oral Disord Ther 2016;4:00104. doi: 10.15406/ jdhodt.2016.04.00104

5. Kinoshita E, Kinoshita-Kikuta E, Koike T. The Cutting Edge of Affinity Electrophoresis Technology. Proteomes 2015;3:4255.

6. Gama MR, Collins CH, Bottoli CB. Nano-liquid chromatography in pharmaceutical and biomedical research. $J$ Chromatogr Sci 2013;51:694-703.

7. Gstaiger M, Aebersold R. Applying mass spectrometry-based proteomics to genetics, genomics and network biology. Nat Rev Genet 2009;10:617-27.

8. Jagr M, Eckhardt A, Pataridis S, Broukal Z, Duskova J, Miksik I et al. Proteomics of human teeth and saliva. Physiol Res 2014;63(1):S141-54.

9. Chiappelli F, Covani U, Giacomelli L. Proteomics as it pertains to oral pathologies and dental research. Bioinformation 2011:5:277. doi: 10.6026/97320630005277

10. Hubbard MJ, Faught MJ, Carlisle BH, Stockwell PA. ToothPrint, a proteomic database for dental tissues. Proteomics 2001;1:132-5.

11. Mathura VS, Kangueane P. Bioinformatics: A Concept-Based Introduction, New York: Springer Science+Business Media, LLC 2009;108-12.

12. Cabras T, Iavarone F, Manconi B, Olianas A, Sanna MT, Castagnola M, et al., Top-down analytical platforms for the characterization of the human salivary proteome. Bioanalysis 2014;6:563-81.

13. Seema S, Krishnan M, Harith AK, Sahai K, Iyer SR, Arora V, et al., Laser ionization mass spectrometry in oral squamous cell carcinoma. J Oral Pathol Med 2014;43:471-83.

14. Mrozik KM, Zilm PS, Bagley CJ, Hack S, Hoffmann $\mathrm{P}$, Gronthos S, et al., Proteomic characterization of mesenchymal stem cell-like populations derived from ovine periodontal ligament, dental pulp, and bone marrow: analysis of differentially expressed proteins. Stem Cells Dev 2010;19:1485-99

15. Salmon CR, Tomazela DM, Ruiz KG, Foster BL, Paes Leme AF, Sallum EA, et al., Proteomic analysis of human dental cementum and alveolar bone. J Proteomics 2013;91:544-55.

16. Dame ZT, Aziat F, Mandal R, Krishnamurthy R, Bouatra S, Borzouie $\mathrm{S}$, et al., The human saliva metabolome. Metabolomics 2015;11:1864-83.

17. Porto IM, Line SRP, Laure HJ, Gerlach RF. Comparison of three methods for enamel protein extraction in different developmental phases of rat lower incisors. Eur J Oral Sci 2006;114(1):272-5

18. Conrads G, Gharbia SE, Gulabivala K, Lampert F, Shah HN. The use of a 16S rDNA directed PCR for the detection of endodontopathogenic Bacteria. J Endod 1997;23:433-8.

19. Siqueira JF, Roças IN, De Uzeda M, Colombo AP, Santos KR. Comparison of 16S rDNA-based PCR and checkerboard DNADNA hybridisation for detection of selected endodontic pathogens. J Med Microbiol 2002;51:1090-6.

20. Munson MA, Pitt-Ford T, Chong B, Weightman A, Wade WG. Molecular and cultural analysis of the microflora associated with endodontic infections. J Dent Res 2002;81:761-6. 
21. Kunin AA, Evdokimova AY, Moiseeva NS. Age-related differences of tooth enamel morphochemistry in health and dental caries. EPMA J 2015;6:3. doi: 10.1186/s13167-0140025-8.

22. Hubbard, M.J.; Kon, J.C. Proteomic analysis of dental tissues. J Chromatogr B 2002;771:211-20.

23. Moradian-Oldak J. Protein-mediated enamel mineralization. Front Biosci (Landmark Ed). 2012;17:19962023.

24. Wald T, Bednarova L, Osicka R, Pachl P, Sulc M, Lyngstadaas $\mathrm{SP}$, et al., Biophysical characterization of recombinant human ameloblastin. Eur J Oral Sci 2011;119(1):261-9.

25. Vymetal J, Slaby I, Spahr A, Vondrasek J, Lyngstadaas SP. Bioinformatic analysis and molecular modelling of human ameloblastin suggest a two-domain intrinsically unstructured calcium-binding protein. Eur J Oral Sci 2008;116:124-34.

26. Brookes SJ, Barron MJ, Smith CEL, Poulter JA, Mighell AJ, Inglehearn $\mathrm{CF}$, et al., Amelogenesis imperfecta caused by $\mathrm{N}$ terminal enamelin point mutations in mice and men is driven by endoplasmic reticulum stress. Hum Mol Genet 2017;26:1863-76.

27. Hu JC, Chun YH, Al Hazzazzi T, Simmer JP. Enamel formation and amelogenesis imperfecta. Cells Tissues Organs. 2007; 186: 78-85.

28. Hu JCC, Yamakoshi Y. Enamelin and autosomal-dominant amelogenesis imperfecta. Crit Rev Oral Biol Med 2003; 14:387-98

29. Farah RA, Monk BC, Swain MV, Drummond BK. Protein content of molar-incisor hypomineralization enamel. J Dent 2010;38:591-6.

30. Widbiller M, Schweikl H, Bruckmann A, Rosendahl A, Hochmuth E, Lindner SR, et al., Shotgun Proteomics of Human Dentin with Different Prefractionation Methods. Sci Rep 2019;9:4457. doi: 10.1038/s41598-019-41144-x.

31. Chun SY, Lee HJ, Choi YA, Kim KM, Baek SH, Park HS, et al., Analysis of the soluble human tooth proteome and its ability to induce dentin/tooth regeneration. Tissue Eng Part A 2011;17:181-91

32. Park ES, Cho HS, Kwon TG, Jang SN, Lee SH, An CH, et al., Proteomics analysis of human dentin reveals distinct protein expression profiles. J Proteome Res 2009;8:1338-46.

33. Kawashima N, Okiji T. Odontoblasts: Specialized hard-tissueforming cells in the dentin-pulp Complex. Congenit Anom (Kyoto). 2016;56:144-53.

34. Petersson U, Hultenby K, Wendel M. Identification, distribution and expression of osteoadherin during tooth formation. Eur J Oral Sci 2003;111:128-36.

35. Boskey AL. Biomineralization: an overview. Connect Tissue Res 2003;44(1):5-9.

36. Surdilovic D, Natarajan P. M, Ille T, Shetty S. R, Adtani P. Non-Collagen Protein in the Dentin Tissue - the Role in the Process of Dentinogenesis. Biomed Pharmacol J 2018;11:8439.

37. Mazzoni A, Pashley DH, Tay FR, Gobbi P, Orsini G, Ruggeri A, et al., Immunohistochemical identification of MMP-2 and MMP-9 in human dentin: correlative FEI-SEM/TEM analysis. J Biomed Mater Res A 2009;88:697-703.

38. Yamakoshi Y, Hu JCC, Iwata T, Kobayashi K, Fukae M, Simmer JP. Dentin sialophosphoprotein is processed by MMP2 and MMP-20 in vitro and in vivo. $J$ Biol Chem 2006;281:38235-43.

39. Lee SK, Lee KE, Song SJ, Hyun HK, Lee SH, Kim JW et al. A DSPP mutation causing dentinogenesis imperfecta and characterization of the mutational effect. Bio Med Res Int 2013, Article ID: 948181, 1-7. doi: 10.1155/2013/948181

40. Lee KE, Kang HY, Yoo SH, Lee JC, Hwang YH, Nam KH, et al., Novel dentin phosphoprotein frameshift mutations in dentinogenesis imperfecta type II. Clin Genet 2011;79:378384.

41. Qin C, Brunn JC, Jones J, George A, Ramachandran A, Gorski $\mathrm{JP}$, et al., A comparative study of sialic acid-rich proteins in rat bone and dentin. Eur J Oral Sci 2001;109:133-41.

42. De Mattos Pimenta Vidal C, Leme-Kraus AA, Rahman M, Farina AP, Bedran-Russo AK. Role of proteoglycans on the biochemical and biomechanical properties of dentin organic matrix. Arch Oral Biol 2017;82:203-8.

43. Haruyama N, Sreenath TL, Suzuki S, Yao X, Wang Z, Wang $\mathrm{Y}$, et al., Genetic evidence for key roles of decorin and biglycan in dentin mineralization. Matrix Biol 2009;28:129-36.

44. Embery G, Hall R, Waddington R, Septier D, Goldberg M. Proteoglycans in Dentinogenesis. Crit Rev Oral Biol Med 2001;12:331-49.

45. Abou Neel EA, Aljabo A, Strange A, Ibrahim S, Coathup M, Young AM, et al., Demineralization-remineralization dynamics in teeth and bone. Int J Nano Med 2016;11:4743-63.

46. Kim Y-K. Bone graft material using teeth. J Korean Assoc Oral Maxillofac Surg 2012;38:134-8.

47. Goldberg M, Hirata A. The Dental Pulp: Composition, Properties and Functions. JSM Dent 2017;5:1079.

48. Yu T, Volponi AA, Babb R, An Z, Sharpe PT. Stem cells in tooth development, growth, repair, and regeneration. Curr Top Dev Biol 2015;115:187-212.

49. Paakkonen V, Ohlmeier S, Bergmann U, Larmas M, Salo T, Tjaderhane L. Analysis of gene and protein expression in healthy and carious tooth pulp with cDNA microarray and twodimensional gel electrophoresis. Eur J Oral Sci 2005;113:36979.

50. Wei X, Wu Lp, Ling Jq, Liu L, Liu S, Liu W, et al., Differentially expressed protein profile of human dental pulp cells in the early process of odontoblast-like differentiation in vitro. J Endod 200;34:1077-84.

51. Sandanayake NS, Sinclair J, Andreola F, Chapman MH, Xue A, Webster GJ, et al., A combination of serum leucine-rich $\alpha$ 2-glycoprotein 1, CA19-9 and interleukin-6 differentiate biliary tract cancer from benign biliary strictures. $\mathrm{Br}$ J Cancer 2011;105:1370-8

52. McLachlan JL, Smith A.J, Bujalska IJ, Cooper PR. Gene expression profiling of pulpal tissue reveals the molecular complexity of dental caries. Biochim Biophys Acta 2005;1741:271-81.

53. Reichenberg E, Redlich M, Cancemi P, Zaks B, Pitaru S, Fontana S, et al., Proteomic analysis of protein components in periodontal ligament fibroblasts. J Periodontol 2005;76:164553.

54. McKnight H, Kelsey, WP, Hooper DA, Hart TC, Mariotti A. Proteomic Analyses of Human Gingival and Periodontal Ligament Fibroblasts. J Periodontol 2014;85:810-8.

55. Wu L, Wei X, Ling J, Liu L, Liu S, Li M, et al., Early osteogenic differential protein profile detected by proteomic analysis in human periodontal ligament cells. J Periodontal Res 2009;44:645-56.

56. Wu LP, Wei X, Ling JQ, Liu L. A differential expression proteomic study of human periodontal ligament cell during osteogenic differentiation. Zhong Hua Kou Qiang Yi Xue Za Zhi 2009;44:212-6.

57. Roi A, Rusu LC, Roi CI, Luca RE, Boia S, Munteanu RI et al. A New Approach for the Diagnosis of Systemic and Oral Diseases Based on Salivary Biomolecules. Dis Markers 2019, Article ID 8761860, 11 pages. doi: 10.1155/2019/8761860

58. Vitorino R, Guedes S, Manadas B, Ferreira R, Amado F. Toward a standardized saliva proteome analysis methodology. J Proteomics 2012;75:5140-65.

59. Prodan A, Brand H, Imangaliyev S, Tsivtsivadze E, van der Weijden F, de Jong A, et al., A Study of the Variation in the Salivary Peptide Profiles of Young Healthy Adults Acquired 
Using MALDI-TOF MS. PLoS One 2016;11:e0156707.doi: 10.1371/journal.pone.0156707.

60. Amado FM, Vitorino RM, Domingues PM, Lobo MJ, Duarte JA. Analysis of the human saliva proteome. Expert Rev Proteomics 2005;2:521-39.

61. Fabian TK, Hermann P, Beck A, Fejerdy P, Fabian G. Salivary defense proteins: their network and role in innate and acquired oral immunity. Int J Mol Sci 2012;13:4295-320.

62. Hannig C, Hannig M, Attin T. Enzymes in the acquired enamel pellicle. Eur J Oral Sci 2005;113:2-13.

63. Fabian Tk, Fejerdy P, Csermely P: Salivary genomics, transcriptomics and proteomics: the emerging content of the oral ecosystem and their use in the early diagnosis of cancer and other diseases. Curr Genomics 2008;9:11-21.

64. Siqueira WL, Zhang W, Helmerhorst EJ, Gygi SP, Oppenheim FG. Identification of protein components in invivo human acquired enamel pellicle using LC-ESI-MS/MS. J Proteome Res 2007;6:2152-60.

65. Amado FM, Ferreira RP, Vitorino R. One decade of salivary proteomics: current approaches and outstanding challenges. Clin Biochem 2013;46:506-17.
66. Al-Tarawneh SK, Border MB, Dibble CF, Bencharit S. Defining salivary biomarkers using mass spectrometry-based proteomics: a systematic review. OMICS 2011;15:353-61.

67. Khurshid Z, Mali M, Naseem M, Najeeb S, Zafar MS. Human Gingival Crevicular Fluids (GCF) Proteomics: An Overview. Dent J (Basel) 2017;5. pii: E12. doi: 10.3390/dj5010012

68. Huynh AH, Veith PD, McGregor NR, Adams GG, Chen D, Reynolds EC, et al., Gingival crevicular fluid proteomes in health, gingivitis and chronic periodontitis. J Periodontal Res 2015;50:637-49.

69. Tsuchida, S, Satoh M, Sogawa K, Kawashim Y, Kado S, Ishige T, et al., Application of proteomic technologies to discover and identify biomarkers for periodontal diseases in gingival crevicular fluid: A review. Proteomics Clin Appl 2014;8:232-40

How to cite this article: Vamsee KN, Madhuri N. Biomarker of health and disease in Dentistry: Proteomics. Indian $J$ Conserv Endod 2019;4(3):69-74. 